\title{
Reforming Education for Economic, Social \& Other Developments
}

\author{
EMDAD KHAN \\ InternetSpeech, Inc, San Jose, CA, USA \\ Coll. of Computer \& Information Science, Imam University, Riyadh, Saudi Arabia \\ emdad@internetspeech.com, emdad@ccis.imamu.edu.sa
}

\begin{abstract}
Today, we are living in a very uneven world - top $1 \%$ rich people own $40 \%$ of the world wealth and top $10 \%$ rich people own over $80 \%$ of the world wealth. $60 \%$ world population (over 4 Billion) is poor. Poverty and hunger levels are highest in Africa. Can this be changed? Can we have a much better world? Can we have a prosperous Africa? The answers to these questions are YES as described in this paper. Although we have focused in Africa, the concept presented can be used for other parts of the world including Asia, Europe, South America and parts of North America. Africa is rich in resources. For example, just Zambia, Uganda or one fifth of Nigeria can feed the whole Africa if agriculture potential is fully exploited. Several African countries have other key resources like minerals (e.g. copper in Zambia). African population, dominated by youths, can be converted into an enormous valuable resource. Thus, there is no real reason why Africa should remain poor.
\end{abstract}

All we need is some Major Paradigm Shifts and associated Educational Reform so that we can fully exploit all the resources and ensure Economic, Social, Cultural \& other developments (including increased peace) and prosperity. In this paper we have proposed key Paradigm Shifts and associated Educational Reform needed to ensure development, eradicate poverty and hunger, and ensure prosperity by creating an enormous resource from the BOP (Base of the Pyramid People) and properly utilizing such resource.

Keywords-Educational Reform; Informal Education; Formal Education; Paradigm Shifts; Rendering; Intelligent Agent; Artificial Intelligence; User Interface; Natural Language Understanding (NLU); Innovation; Entrepreneurship; Economic Development; Social Development; e-Learning; Base of the Pyramid People (BOP)

\section{INTRODUCTION}

The need for education, especially for economic, social, cultural and other developments is self explanatory. The need for education is even more important and critical for Africa where poverty is highest whereas the continent has ample resources, and population is dominated by youth. It is clear that existing education is not adequate (as otherwise poverty level would not be highest) even though it is playing a major role. From educational reform standpoint, we need to focus not just on formal education but also on informal education, especially for the BOP (Base of the Pyramid People) as their number is huge, they are the backbone of the development and they can be converted into an enormous resource. In fact, to achieve our objectives, the reform needed seems to be significant both for formal and informal education. Moreover, reform for the formal education is also tightly coupled with the reform for informal education as explained below.

Existing formal education, in general, is geared towards Western Curricula which in most cases does not show highly effective results for the underdeveloped and developing countries. For example, students graduating in engineering and computer science do not find enough jobs in their own country as there are not many relevant industries. On the other hand, they cannot easily go to Western world and try to get jobs there. A few who might be able to go to some Western countries would first need to get some advanced degrees before competing for some jobs. Thus, they can neither go to Western countries and find jobs there nor they can find jobs in their own countries. Due to the lack of entrepreneurship and innovation, there are not many new companies to attract outsourced projects. Some of these issues are also well applicable for general science and other majors. Thus, continuing with the existing way, there will be more graduates using country's valuable resources but with more unemployment (i.e. more graduates than number of jobs), resulting in negative Economical, Social and other impacts.

Education empowers a person and helps to become proactive, gain control of the life and broaden the range of available options. Education is recognized as a basic human right. Education is the key for innovation, entrepreneurship, productivity improvement and resource creation. And education is even more important for the BOP as already mentioned.

In general, education is even more important for women and children as they are less likely to receive medical services, clean water, sanitation and other services. Education is equally important for the people with various disabilities to help them become more independent, getting employed, avoid social exclusion and getting entertained. And, of course, education is good and important for all other types of people.

The key point is to reform education to meet our objectives including economic, social, cultural and other developments with increased world peace in a sustainable way with good growth, and thus ensuring prosperity.

Apart from educational reform, we would also need some Major Paradigm Shifts so that we can fully exploit all the resources and achieve our objectives. Hence, we have focused on the Paradigm Shifts ([9]) and associated Educational 
Reform ([1], [12]) needed to ensure development, eradicate poverty and hunger, and ensure prosperity by creating an enormous resource from the BOP (Base of the Pyramid People) and properly utilizing such resource.

- The 1st paradigm shift is the fact that Africans (and BOP in general) can be "producers" and not remain as "consumers".

- The 2nd paradigm shift is to effectively bridging the Digital and Language Divides using Voice Internet.

- $\quad$ The 3rd paradigm shift is that just bridging the Digital and Language Divides will not be enough; we need a complete, fully integrated strategy to tie all these along with Education, Innovation and Entrepreneurship.

- The 4th Paradigm Shift is that agriculturally resourceful countries need to highly emphasize on Agriculture as it can make such countries really prosperous.

Education is a key component to nicely and effectively tie all above and develop knowledge from the information. It is also a key component for innovation and entrepreneurship. To stimulate real economic growth, "education” needs to be highly emphasized and targeted, especially with "creativity", "productivity" and "resource" creation in mind. Creativity will in turn drive innovation, entrepreneurship, productivity and more. And we need to focus on both formal and informal education to ensure that the Base of the Pyramid People (BOP) are active part of this process.

Section II provides highlights of the reform, Section III discussed details of the reform, Section IV discusses the need for a good Business Model so that all Components Work in Harmony, Section V describes keys tasks needed for the proposed reform and Section VI describes expected outcome and impact.

\section{HIGHLIGHTS OF THE EDUCATIONAL REFORM}

Our theme on the reform can be summarized with the following:

- $\quad$ Provide country specific Applied Education that can show results immediately - Job Creation, Economic, Social, Cultural \& other Developments with Prosperity.

- Utilize the access to information to knowledge, use knowledge to drive innovation \& entrepreneurship to finally drive the development. Education is a key component to develop knowledge from the information. It is also a key component for innovation and entrepreneurship.

Thus, education is a very important key element. To stimulate real economic growth, “education” needs to be highly emphasized and targeted, especially with "creativity", "productivity" and "resource" creation in mind. Creativity will in turn drive innovation, entrepreneurship, productivity (and even resources - like discovering new oil reserve, alternate energy...) resulting successful business entities which in turn will create jobs and drive economy reducing rich-poor gap. In a nut shell, the key idea is to provide "appropriate education" to all \& use the benefits of getting appropriate education to create valuable resources [1]. And to ensure education for all, easy and affordable access to the Internet is a must.

\section{A. Fostering Education}

The importance of education has been growing since human civilization. It is the cornerstone for growth and ensures sustainable development. Unfortunately, the education systems in the underdeveloped and developing countries, in general, are further behind than the educational systems in developed countries. Many of the world's children receive no formal education or a sub-standard education. Many lack books, materials and have no or little communication with the wider world. The course curricula is based on old method of traditional non digital books, old text books and subjects/courses, lecture method with writing on blackboards, no lecture notes, limited homework mainly from the text book and the like.

So, in fostering education there are quite a few issues that would need to be addressed. A few important ones are:

- Improved courses, especially meeting country's need and not just blindly following Western curricula.

- Improved teaching / lecturing methods to ensure learning.

- Access to library and digital information sources including, the Internet.

- Management of college / university system using computers to improve efficiency and accuracy.

- Much more frequent update of course curricula by following the same from rich education system as well ensuring that local needs are properly met.

- Introducing distance learning.

- Formal courses to teach the teachers with new courses and methods.

- Allowing students to use Internet at home to help improve their study, solving home works, writing reports and the like.

- Special emphasis on "informal education" as many people at the base of the pyramid cannot afford to go to school for a long time to get a formal degree.

- Ensure that education is also closely related to job needs and growth. 
- Ensure that education is also strongly focused on entrepreneurship and innovation.

- $\quad$ Strong emphasis on immediate, short term and long term needs.

\section{B. Fostering Innovation}

Education is great and essential but not sufficient to have great impact. E.g. even after everybody is well educated, most possibly there will be more job seekers than number of jobs. So, education itself will not solve the ultimate goal of great economic development.

Innovation is a very important element to apply education in a manner it is impactful in solving some key problems in more efficient ways, and thus, help many people and in turn help economic growth. Innovation does not need to be at high level - it can be at all levels. So, there is no need to think that only certain highly educated people can do innovation. In fact, many illiterate people can be very innovative in solving their key problems. This is why we would need to emphasize on both formal and informal education as many people at the base of the Pyramid can become innovative faster using informal education.

Similarly, higher education is key for innovation at high level. Thus, graduate studies in key subject areas including science, engineering, medicine, and business are very important. A pure technical innovation may not be effective in producing good results unless there are also innovation in marketing, sales and business development.

Innovation needs to be in almost everything including improving various types of existing systems (transportation, communication, business processes, ..), automating various processes (economic, social,...), coming up with new product or business ideas (in the local, regional or global contexts), and research. Thus, we would need to make innovation as part of our culture.

\section{Fostering Entrepreneurship}

Innovation \& Education alone cannot really make things happen unless innovations are implemented using a sound business model. Thus fostering "entrepreneurship" using innovation is the key to take full advantage of innovation developing products and services, deploying them to the users, ensuring that such products and services are beneficial to the users \& society, and thus helping social, economic, cultural and other developments. These will also help monetize the innovation. Entrepreneurship will help graduates to start companies and create jobs rather than look for jobs (proposed educational reform with special focus on innovation and entrepreneurship will help this process). Like innovation, entrepreneurship should also be at all levels.

\section{DETAILS OF THE PROPOSED REFORM}

The proposed reform is driven from 4 major perspectives (Fig. 1):

- $\quad$ Meet the immediate and future needs of the country

- Flexible education with focus on Multi-disciplinary, Innovation and Entrepreneurship

- $\quad$ Strong linkage to the Industry

- Serve all population (BOP, Youth, Women, Disabled, Elderly,..) , organizations (including Government, NGOs,...), Institutions (Universities, Schools, Research centers ,...)

To meet the key needs of a country in an underdeveloped and developing world (especially in Africa), we need to focus on Agricultural Economy (with high emphasis), Industrial Economy (Mining, Manufacturing,..), Information \& Knowledge Economy ( IT \& Software development / outsourcing) and Intelligence Economy (Research and Development). The near term focus needs to be on the first 3. Intelligence economy will be mainly for long term. Clearly the $2^{\text {nd }}$ and $3^{\text {rd }}$ are strongly coupled and tied together with Agricultural, Industrial and Knowledge Economy to meet $1^{\text {st }}$ and 4th.

Additionally, there will be continuous reform for course curricula, continuous reform in the industry (and its linkage) and new resources will be created also on a continuous basis. Education also needs to be focused to ensure good learning as otherwise education is not really effective. Hence, new teaching and research methods also need to be included to ensure learning and effectiveness of education.

Thus, the proposed reform is a well integrated approach that addresses all key issues in a coherent way and ensures Economic, Social, Cultural and other developments with Educational Institutions playing a major and much increased well deserved role. We have started implementing the proposed reform in some African countries including Zambia.

\section{A. Course Curricula Change}

To achieve our vision, objectives and goals, course curricula need to be changed across all major disciplines. However, we need to do so in various steps, preferably in 3 phases (as described below). In the first phase, we propose to address Computer Science, Information Science, Information Management / Systems and Business. In the 2nd phase, changes in the Engineering discipline and Science discipline can take place. However, it is recommended to start making some changes in the Engineering discipline and also in the Science discipline (especially Agriculture) in the first phase. 


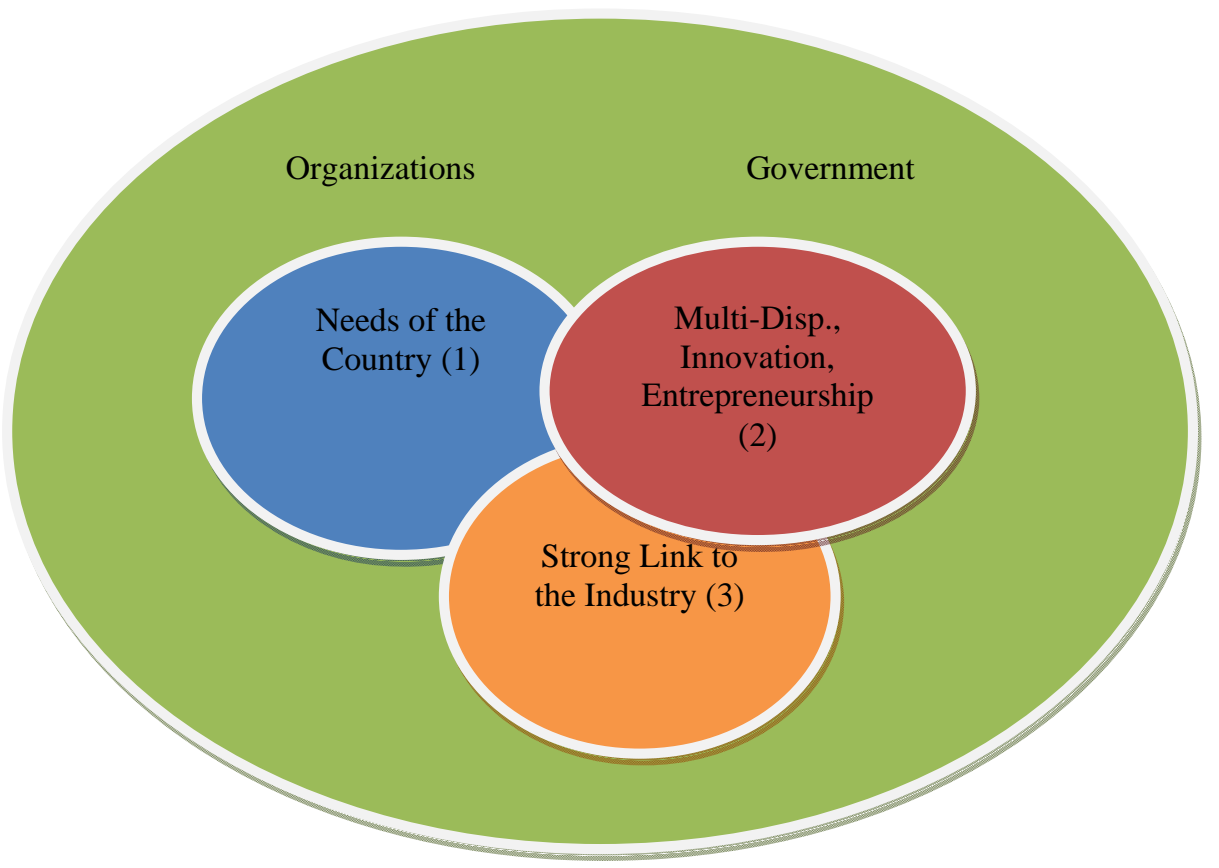

Fig. 1 Key Features Driving Proposed Educational Reform

In the $3^{\text {rd }}$ phase changes in other key disciplines can take place.

1) Course Curricula Change in Computer Science, Information Science, , Information Management / Systems and Business

We propose to have a few multi-disciplinary courses as "core” mandatory courses. Such multi-disciplinary courses will include at least two courses on Entrepreneurship, one course on Innovation, one course on Agriculture, one course on Industry (preferably mining) and one course on Business. There will be 2-3 types of degrees:

- Basic BS with the "core” multi-disciplinary courses

- BS with more multi-disciplinary and Business focus (this will have courses in other areas including Economics, Finance).

To ensure that we do not exceed total units needed to get a BS degree, appropriate number of units will be cut from the current curricula - especially those courses that do not help country's needs much.

Master's and $\mathrm{PhD}$ curricula will be changed in the same way with more emphasis on applied research for the Thesis.

\begin{abstract}
Also, to encourage employees from industry can continue their higher education, students will be enrolled to do Masters and $\mathrm{PhD}$ degrees on part-time basis. Additionally, a Masters program without a Thesis option can be added to help students from the Industry to better participate in graduate study.
\end{abstract}

\section{B. E-Learning Needs}

As already mentioned education is the key for various developments. In today's environment e-Learning based education is becoming very important for various reasons including lowering cost, minimizing travel time, providing flexibility in taking classes and completing degrees, allowing easy lifelong learning and more. Accordingly, e-Learning has become popular not just for traditional degree programs for the educating / educated class but also for the semi-literate and illiterate class.

\section{1) Base of the Pyramid People, e-Learning and Poverty}

The need for education for the BOP (Base of the Pyramid people) to eradicate poverty \& hunger, minimize rich-poor gap, improve health, improve quality of life and more is obvious. Education is the key for economic, social, cultural and other growths. Education empowers a person and helps to become proactive, gain control of the life and broaden the range of available options. As already mentioned, education is recognized as a basic human right. Education is the key for 
innovation, entrepreneurship, productivity improvement and resource creation. Questions is "how to provide education to such a big population in a practical and effective way?”

\section{a) Existing Approaches and Critical Issues}

Many organizations around the world have been very active in providing education to the poor. Such organizations include the United Nations, World Bank, Governments, NGOs, Foundations, Non-profit entities, Corporations, Universities and Research Institutions. They usually provide help in various ways including special summer classes, special courses, equipments, books and other related materials. In addition to teaching via face-to-face classes, some of these organizations also provide various help with e-Learning. These efforts are well aligned with the following conclusion:

"There is no way the world can succeed in eradication of poverty if the developing world is not part of the knowledge creation, its dissemination and its utilization to promote innovation"

Made by both the United Nations Millennium Project Task Force and the World Bank after conducting some good research.

Since traditional classroom based education for the poor is expensive, although very important, we focus here mainly on eLearning.

One good source describing various efforts on conventional education as well as e-Learning education for the poor is [4] where authors provide a good summary of the current efforts and some good recommendations in moving forward with eLearning. All such recommendations are geared towards mainly literate people, use of existing e-Learning framework and existing approaches to access the Internet, which is mainly dominated via using a computer. While such recommendations are great and should be continued, these would not provide a practical affordable solution to the poor for the following key reasons [8]:

- $\quad$ Poor (BOP) do not have access to computers.

- Most of the BOP are illiterate.

- Most rural areas do not have Internet Access.

- Most e-Learning courses are formal courses geared for the literate people.

- Most e-Learning courses are in English.

- No noticeable focus on Innovation and Entrepreneurship.

Thus, we would need to address the problem by focusing on the following:

- Effectively address the issues of bridging the Digital and Language Divides to ensure easy access to the Internet through a ubiquitous device like a simple phone.

- Use voice and natural language for interaction as many BOP are illiterate.
- Focus mainly on "informal education" as BOP would need something affordable, simple and quick that would help them much sooner than going through some formal degrees or certificates.

- Focus on some good “Automated Methods" to ensure that content delivery, use, teaching and learning are simple, natural and easy.

- Focus on e-Learning mainly as it would be the best way to provide information and education to such a large group of population.

- $\quad$ Focus on Innovation and Entrepreneurship as these are critical to expedite and sustain development.

\section{2) A Practical and Effective e-Learning Solution for BOP}

We believe our proposed solution using Voice Internet eLearning (as described below) would effectively meet all above needs, and hence would be a good, affordable and practical solution as well supported by the existing users of Voice Internet. Voice Internet ([1], [2], [3]) is a way to access the Internet by making a phone call using any phone and then talking and listening to the Internet. One can Surf, Search, do email, conduct e-Commerce and more.

Voice Internet overcomes the difficulties mentioned above with existing approaches:

- $\quad$ no need to buy a special device (thus allowing easy \& affordable access to many more people)

- $\quad$ no need to deal with small screen or small key pad as users basically talk and listen

- much easier to learn as learning how to use a phone is much simpler than learning how to use a computer or personal device

- $\quad$ no need to re-write the content in another language. There are over 3 billions of websites on the Internet. Re-writing all of them would be very expensive and hence not practical

- no requirement to know how to read or write

The other key challenge that Voice Internet overcomes is the "rendering" problem. Rendering or converting such information into short, precise, easily navigable, meaningful and pleasant to listen to content is a very hard problem that Voice Internet has overcome. These key features of rendering are very important as when listening, one does not have time to listen to everything on a page, would like to move around easily and quickly and make sure that content heard is the content that was desired.

a) Proposed e-Learning Solution for the BOP using Voice Internet

Our proposed e-Learning solution [8] is built on the Voice Internet technology as it addresses some of major issues related to the BOP in providing effective education via e-Learning, namely, 
- Help bridges the Digital and Language Divides in an effective way to ensure easy access to the Internet through a ubiquitous device like a simple phone.

- Uses voice and natural language for interaction.

- $\quad$ Renders content into Short, Precise, Easily Navigable and Meaningful content.

- Users basically talk and listen to the Internet using their voice and hearing.

These key features available in Voice Internet are enhanced with an augmented Intelligent Agent to handle the e-Learning needs. Thus, the Voice Internet e-Learning Intelligent Agent (VIELIA, Fig. 2) addresses the following additional issues:

- Focus on some good “Automated Method” to ensure that content delivery, use, teaching and learning are simple, natural and easy.

- Uses Question and Answer type System Approach in the domain of Interest.

- Focus mainly on "informal education/courses" as BOP would need something affordable, simple and quick that would help them much sooner than going through some formal degrees or certificates.

- VIELIA also focuses on "formal" existing e-Learning courses but with better delivery and user interaction.

- Focuses on Innovation and Entrepreneurship as these are critical to expedite and sustain development.

These additional features are achieved by using better content management, enhanced dialogue design, enhanced rendering, Natural Language Understanding, Q\&A approach and an automated way to improve performance over time using some self-learning.

3) Role of Universities and other Educational Institution for E-Learning

While many universities have started offering e-Learning courses, they are mainly focusing on the formal courses geared for the educated class. Currently there are no e-Learning courses for the BOP that we are aware of. However, there are some good informational materials available via radio and Voice Portal.

We propose universities and other educational institutions to start providing e-Learning courses for the BOP to expedite the process, save cost, and make it more efficient and practical. In addition, such educational institutions can provide some certificate programs so that in the long run BOPs can start competing in the higher end jobs.

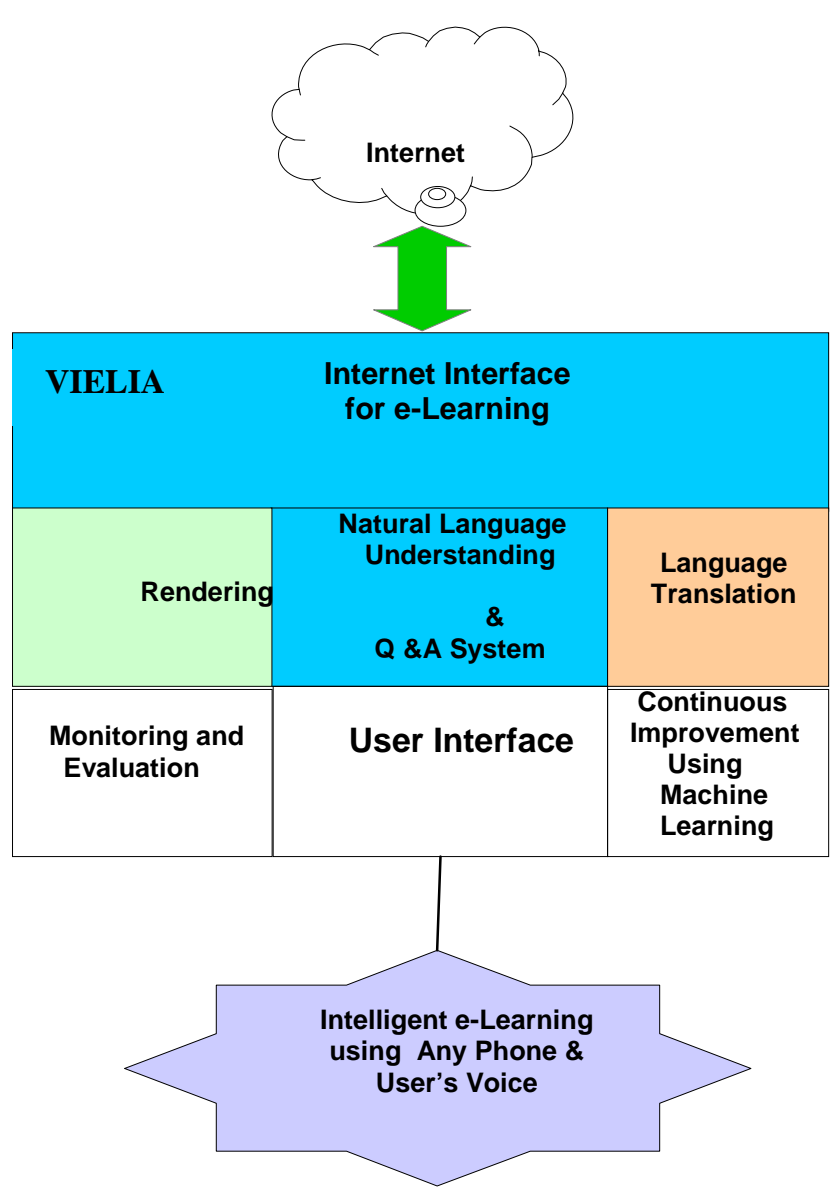

Fig. 2 Voice Internet based e-Learning Intelligent Agent (VIELIA)

In doing so, educational institutions will also develop corresponding higher level courses for the undergraduate and graduate programs - e.g. to teach famers how to preserve tomatoes or make milk products, there will be corresponding higher level courses to ensure that such processes are scientifically based, tested properly and provide good yields. Similarly, to let the farmers sell their products directly to the customers using on-line portals, new smart portals with special easy user Interface for the BOP would need to be developed. This involves multiple high level problems and various key technological challenges - e.g. Advanced algorithms, Artificial Intelligence, Software engineering and Machine Learning would be needed to solve associated problems. And this is a great opportunity for the educational institutions as whatever appropriate courses are needed to be developed and offered will be directly linked to the practical applications helping economic and social developments and impacting all people as well stated for our vision and goals. The educational institutions can be proud of their proposed contribution in this regard.

To expedite and facilitate the process for maximum penetration, such education institutions should include all other related organizations. Moreover, they can inspire and help to 
form new educational entities (and some of them can be from the BOP themselves) to further facilitate the process.

\section{ENSURE A GOOD BUSINESS MODEL SO THAT ALL COMPONENTS WORK IN HARMONY}

As shown in Fig. 1, all key components are tied together and people across (1), (2) and (3) need to closely work together to achieve key objectives. But these are all different organizations / institutions / companies. How can we ensure that all will work in a harmony? Well, we basically need a good Business Model. Each entity has its own business model. But we need to develop a new business model so that all entities can work in a coherent way to achieve their objectives. A good example is allowing and encouraging faculty oriented business.

\section{A. Faculty Oriented Business}

Faculty initiated business is very common in US, especially in the Silicon Valley. For example, Sun, Yahoo and Google were founded by Stanford faculties and students. Faculty initiated business is more important and very key for African countries as

- There are not many potential entrepreneurs from the industry compared to the Silicon Valley.

- Faculties are not equipped with needed knowledge to help start new companies and help drive "entrepreneurship" and "innovation".

- $\quad$ Some universities (e.g. UNZA - University of Zambia) already have some courses on "entrepreneurship” and "innovation".

- Future technology based businesses will be driven mainly from "multi-disciplinary" education standpoint as products and services are getting more complex and many diversified fields are merging (a good example is Stanford University's Bio-X project, the first "marriage" between the engineering and medical schools, which started about 6-7 years ago and then followed by MIT, U.C Berkeley and more institutions). Thus, faculties would be more appropriate to start future new start-ups.

To support this process, we would also need to start multidisciplinary courses and degrees as already mentioned in this paper. The first few such multi-disciplinary programs and degrees should include CS, Information Science / Systems, Engineering and Business.

Additionally, when faculty members get involved in business (of course without lowering their efforts for teaching and research), all components in Fig. 1 will be coupled more tightly, thus helping better achieving the goals. It will also provide faculty members high incentive to drive their businesses as they will get additional income to help their current lower level salary; they will see clearly how they can really help in several areas and continuously make necessary changes in the academic programs to help economic and other developments.
We need to put some good efforts to develop a good business model so that all such entities work together in a coherent way. This will be one of the key tasks.

\section{B. University as Business Entity}

We need to think universities as business entities. Such institutions may get funding from outside sources as appropriate BUT should NOT fully depend on funding from outside sources. Such institutions should run them as private Universities or institutions. The proposed Faculty oriented business in Section IV, part A will help this process in a significant way as for each faculty oriented business, part of the Contributions will go to the University.

\section{KEY TASKS}

\section{A. Updating Course Curricula-}

Update existing course curricula for various disciplines as described in Section III,. part A. This includes adding proposed multi-disciplinary courses and removing courses that are not appropriate for the objectives defined. It is proposed to start with Computer Science department first and then add other departments as described in III. Part A.

\section{B. Updating course content -}

Update course content for various disciplines. Start with CS, Information Science /System, Engineering and Agricultural and Mining sciences. Course content in CS is old in general. Since we are talking about ICT driven farming, ICT driven mining, CS course content needs to be updated accordingly.

\section{Updating Degree Programs -}

Update / introduce new degree programs as described in Section III, part A. Start with CS and Business first.

\section{Enhancing Faculty \& Staff -}

Hire necessary number of good faculty members and staff to support proposed new programs. This needs to be done for first 5 years with external funding, and proposed faculty based business and other related programs should make the process sustainable with its own revenue, with an intention of good growth after first 5-year is completed.

\section{E. Establishing Research Institutes -}

It is important to establish key research institutes to ensure research efforts well aligned with the Vision, Mission and goals.

\section{F. Aligning with the Industry and Basic Needs of the Country $-$}

As shown in Fig.1, proposed courses and programs need to be well aligned and coordinated with country's basic needs and the industry. A good level of efforts would be needed from the universities and other educational institutions. Similar efforts will be needed from the industry, Government and other entities. 


\section{G. Developing a Good Business Model -}

As already described, developing a good business model is key to ensure that all involved entities work together in a coherent way to achieve their shared goals.

\section{H. Adding E-Learning Capabilities -}

As described in Section III, part B (2) [A Practical and Effective e-Learning Solution for BOP], we would need a major effort for e-Learning based education, especially for the BOP. This will include defining, developing, offering and regularly updating \& enhancing many e-Learning courses and programs.

\section{EXPECTED RESULTS AND IMPACT}

A sustainable eco system with good growth involving all key components including Academia and Industry working in harmony to achieve Economic, Social, Cultural and other developments with increased peace. Development will be realized by creating a huge resource from the BOP and using that resource in the new entrepreneurship and innovation driven businesses, well aligned with country's needs and existing available resources.

Universities and other educational institutions will play a major role by moving from just providing traditional education to providing applied education to both literate and illiterate people and help all components (Fig. 1) glued together in a sustainable way with good growth.

The nations will become "producers" and not just remain mainly as "consumers". Many people will get out of Poverty and Hunger, Unemployment rate will come down significantly and African countries and also countries from rest of the world will become leaders in making good changes for sustainable development and prosperity.

\section{REFERENCES}

[1] E. Khan, "Internet for Everyone - Reshaping the Global Economy by Bridging the Digital Divide”, Book - ISBN 978-1-4620-4251-7 (SC ISBN )978-1-4620-4250-0 (HC ISBN), Aug 2011.

[2] E. Khan, "Information for Everyone using any Phone - Global Development via Education, Entrepreneurship and Innovation", International Convention on Rehabilitation Engineering \& Assistive Technology in Collaboration with ACM, July 2010, Shanghai, China.

[3] E. Khan and E. Aleisa, "e-Services using any Phone \& User's Voice: Bridging Digital Divide \& help Global Development”, IEEE International Conference on Information Technology and e-Services, March 24-26, 2012, Tunisia.

[4] H. Khan et al, "Poverty, Poverty Alleviation and Social Disadvantage: Analysis Case Studies and Policies", edited by C.A Tisdell, Serial Publications, New Delhi, 2007.

[5] E. Khan, "Very Affordable and Easy to Use Internet for Everyone using any Phone: Ensuring Social Inclusion for People with Disabilities", ITU Asia-Pacific Forum, Aug 25- 27, 2009, Bangkok, Thailand.

[6] E. Khan, "System and Method for Audio-Only Internet Browsing using a Standard Telephone”, U.S. Patent Number 6,606,611, Aug 12, 2003.

[7] J. Stiglitz, "Making Globalization Work", W.W Norton \& Company, ISBN 13:978-0-393-06122-2, 2006.

[8] E. Khan. "Education for the Base of the Pyramid People (BOP) using Voice Internet e-Learning”, Procedia - Social and Behavioral Sciences Journal and International Educational Technology Conference”, July 1113, 2012, Taiwan.

[9] E. Khan, "An Intelligent Agent based Farming Mega Portal: A Necessity for Farmers ", 12th WSEAS International Conference on APPLIED COMPUTER and APPLIED COMPUTATIONAL SCIENCE (ACACOS '13), April 2-4, Kuala Lumpur, Malaysia.

[10] E. Khan, "Intelligent Internet: Natural Language and Question \& Answer based Interaction", INTERNATIONAL JOURNAL of COMPUTERS AND COMMUNICATIONS, (NAUN \& UNIVERSITY PRESS) Oct. 2013

[11] E. Khan, "Addressing Big Data Problems using Semantics and Natural Language Understanding", 12th WSEAS International Conference on TELECOMMUNICATIONS and INFORMATICS (TELE-INFO '13) in Baltimore, MD, USA, September 17-19, 2013.

[12] InternetSpeech, "A Proposal for Educational Reform for Economic, Social and Other Development", Presented to University of Zambia, 2012. 